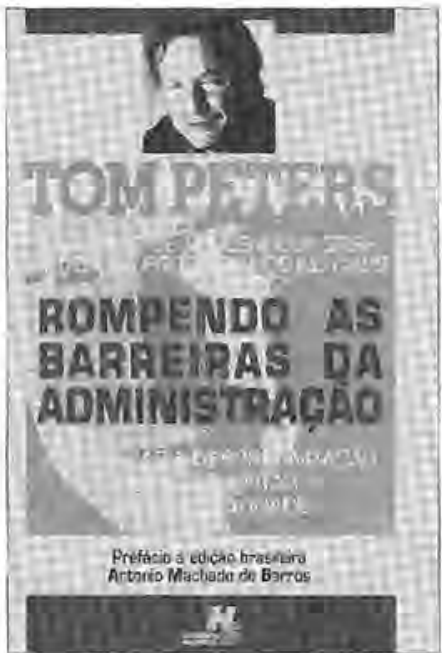

\section{ROMPENDO AS BARREIRAS DA ADMINISTRAÇÃO}

\section{de TOM PETERS}

São Paulo: Harbra, 1993, 868 p.

\section{por Mirtes Cristina Alves dos Santos,}

Mestranda em Administração de Empresas na USP.

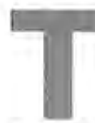

om Peters, um dos mais renomados "gurus" da atualidade, co-autor dos livros Vencendo a crise (com R. H. Waterman Jr.) e A Passion for Excellence (Nancy Austin) e autor de Prosperando no Caos, agora se utiliza de sua experiência como consultor de empresas para elaborar Rompendo as Barreiras da Administração. Da análise de dezenas de empresas, de pequeno, médio e grande portes, não só estabelecidas nos Estados Unidos, em diversas áreas de atuação, e, principalmente, que estão criando uma presença global significativa, discorre suas idéias como resposta às novas necessidades e tendências mundiais.

A princípio, percorrer o número de páginas do livro pode parecer um desafio. No entanto, ao se iniciar a leitura, percebe-se o estilo pouco convencional para um livro de administração. $O$ autor de uma maneira informal, nova e estimulante, entremeia a análise de estratégias utilizadas por empresas e declarações atuais de intelectuais e empresários publicadas nos principais jomais e revistas especializados, além de mesclar fatos e histórias pitorescos. No meio de todos estes elementos, comenta, critica, provoca, discorrendo e argumentando suas idéias, de forma que cada nova seção seja năo-linear e inusitada.
O autor crê que as organizações, em um futuro próximo, deixarão de ser como as conhecemos atualmente. A discussão principia com a constatação de que o ambiente empresarial está mudando rapidamente. Os mercados encontram-se fragmentados, em constante renovação, no qual ciclos de vida de produtos de seis meses não são raros. Os produtos são reinventados e materiais, transformados. Além disso, a competição crescente e de forma global, os custos fora de propósito, a tecnologia de informação, que se desenvolve rapidamente, e o rítmo da necessária especializaçāo representam uma ruptura clara com os modelos organizacionais tradicionais.

Essas pressões, segundo o autor, requerem novas abordagens, novas idéias. O pensar de maneira cartesiana, linear, tradicional, não mais atende aos novos requisitos: a necessidade de inovaçăo, adaptabilidade e flexibilidade que a natureza fluida de mercado requer.

Neste contexto, colocando-se como observador e crítico, Peters analisa casos de empresas que agiram, sob seu ponto de vista, de forma acertada em termos de competitividade, discutindo estratégias gerais de negócio e redefinindo, nos seis capitulos do livro, conceitos como organização, produto $e$ mercado, valor e revisitando temas como fabricação, estrutura e formas de trabalho.

$\mathrm{Na}$ perspectiva do autor, as novas organizaçōes são máquinas de processamento de informaçōes puras. Elas são constituídas por grupos que, de algum modo, e por um momento, formam uma coalizão e executam um determinado serviço. Tornamse, portanto, a criação de conexóes entre o produto e o consumidor. A empresa é, assim, entendida como um pacote de atividades de atendimento. Estas, sob a nova perspectiva, e não a fabricação, provêem a maior fonte de beneficios para os clientes. A empresa de serviços profissionais transformam-se no modelo para a sobrevivência futura, particularmente as agências de propaganda ou consultoria, pois nelas a maior parte do trabalho é realizada por equipes multifuncionais de projetos que utilizam a inteligência coletiva para satisfazer aos clientes.

Do mesmo modo, a definição de produto e serviço está mudando e o autor, ao se referir a eles, utiliza-se de expressōes próprias, buscando sensibilizar o leitor quanto à "nova realidade". Por exemplo, o termo soft inclui as ferrameritas para a criaçăo de produtos atualizados, as ligações instantâneas entre produtores, fornecedores e distribuidores; é a inteligência "embutida" nos produtos. Indica também a ênfase no design industrial e na facilidade de utilização dos produtos, bem como os novos métodos de estabelecer alvos de marketing por meio de sistemas especializados. Os bens materiais conver- 
tem-se, sob este ponto de vista, em contenedores ou veículos para o conhecimento. Um produto mais vantagens soft resulta em um novo produto, sendo que os intangíveis fazem a diferenciação, ficando o hard em segundo plano. Outro termo, "simbiose" indica a estratégia de se estar mais do que "junto" do cliente, de a ele se entrelaçar, construindo um relacionamento interativo. Já "moda" significa o lançamento de uma variedade de "produtos", cada qual destinado a atender às necessidades sempre diferentes e cada vez mais personalizadas. Além disso, para o autor, o sucesso ou fracasso de um produto deve-se a uma longa cadeia de circunstâncias totalmente imprevisivel e à redução do ciclo total de um produto, desde as vendas atế a entrega, é obtida por intermédio da maior criatividade no processo e da integração de funçōes, desenvolvimento do produto, não mais seqüencial, mas simultâneo, por intermédio da reunião dos participantes-chave desde $o$ inicio do projeto.

Neste ambiente transitório, o conhecimento, integrado tanto dentro quanto fora da empresa, e aplicado rapidamente, é a fonte de quase todo o valor econômico. A matéria-prima se rende ao poder intelectual como fonte de valor que cada vez mais e atribuido a "intangiveis". Desta forma, o trabalho intelectual domina cada vez mais na criação do valor econômico,

Com relação à fabricação, o autor coloca que as ferramentas industriais informatizadas freqüentemente permitem que economias de escala sejam obtidas em pequenas instalações e proporcionem um atendimento personalizado à grande "massa". Desta forma, a produção em massa abrange a personalizaçăo. A economia de escala continua sendo perseguida, mas agora na aprendizagem e não na produção. Ela está igualmente associada à capacidade de contatar rapidamente pessoas e organizaçōes. Ele prevê que no futuro não haverá diferença entre fábrica e empresas de serviços.

A discussăo sobre estrutura é a mais extensa, recebendo atençã̃o de quase metade das páginas. $O$ autor enfatiza repetidamente que a desintegração é a resposta à acomodação e ao status quo. As unidades de negócio, os buckyborgs, e o brainuare, o conhecimento e a informaçäo, configuram-se como a base da competência. $O$ modelo está em uma estrutura descentralizada constituida por unidades centralizadas e flexiveis, pequenos centros de lucro, ágeis, próximos ao mercado, que assumem responsabilidades e fazem tentativas inusitadas. Essas empresas não têm quadros organizacionais, descrições de cargo, manuais de política, conjunto de procedimentos, organizam-se, eliminando partes não adaptadas dos portfólios, criando unidades subsidiárias mais autônomas e cortando staffs. São empresas com foco restrito e de tamanho modera- do, concentradas em se tornarem enxutas e em tarefas centrais. Muito de sua excelência está em sua habilidade de recrutar e selecionar contratados e em identificar quanto delegar a terceiros sem perder a distinção. Desta forma, o tamanho, medido pelo poder de mercado de uma empresa, passa a ser função da família de empresas a que se associa e não mais daquilo que se possui ou controla.

Quanto ao gerenciamento do trabalho, o autor é categórico em afirmar que as equipes funcionais desaparecerão, dando origem a uma estrutura amebóide, na qual deve-se aprender a trabalhar em equipe. Cada pessoa participa do processo com uma noção de negócio e com muito mais autorida de. $O$ trabalhador médio apresenta novos requisitos: deve ser multifuncional, dominar uma área de competência especial e transmitir seu conhecimento aos outros. $O$ gerente, neste contexto, também assume um novo papel, o de consultor, criando projetos e administrando sistemas intelectuais.

Como podemos constatar, Tom Peters apresenta uma abordagem organizacional estratégica e abrangente como forma de se ajustar aos novos "requisitos e para se atingir a excelência. Sintetizamos alguns dos principais fundamentos ressaltados:

- as redes de informação serão decisivas para a relativa competitividade futura. A vantagem estratégica reside na aquisição e no controle da informação;

- a excelência advếm apenas quando se ouve o usuário final e o respeita (a "clientização");

- a essência da estratégia não é a estrutura dos produtos e mercados de uma companhia, mas a dinâmica de seu comportamento;

- o poder e a vantagem competitiva residem nas conexóes;

- o sucesso no mercado é diretamente proporcional ao conhecimento que uma organização pode deter à rapidez com que pode adquiri-lo;

- não supor que as coisas possam ser planejadas é fundamental;

- a concepção de organizaçăo, como a formulação da estratégia, é mais orgẩnica e da base para a cúpula. A dimensão humana é a mais importante;

- a equipe executiva deve trabalhar na desintegração para permanecer inovadora e flexível.

Rompendo as Barreiras da Administraçäo prega, reiteradamente, uma mudança de abordagem como forma de atender aos novos requisitos, como saida plausivel para que as empresas sobrevivam e pros. perem em um ambiente de competiçâo acirrada.

A obra destina-se a estudantes, administradores e empresários interessados em conhecer e refletir sobre uma perspectiva nada tradicional dos principais temas da administração, quer através da expe- 
riência prática relatada em situações veridicas nos casos, quer por intermédio da análise dos conceitos $\mathrm{e}$ instrumentos propostos.

A leitura da obra é recomendada, não só pelo aspecto revolucionário da proposta, que provoca profundas repercussōes na gestão de negócios, mas também pela atualidade dos temas abordados. $\mathrm{O}$ modelo e o conjunto de referência promovem o debate e o raciotínio especulativo sobre situaçōes peculiares enfrentadas pelo administrador.

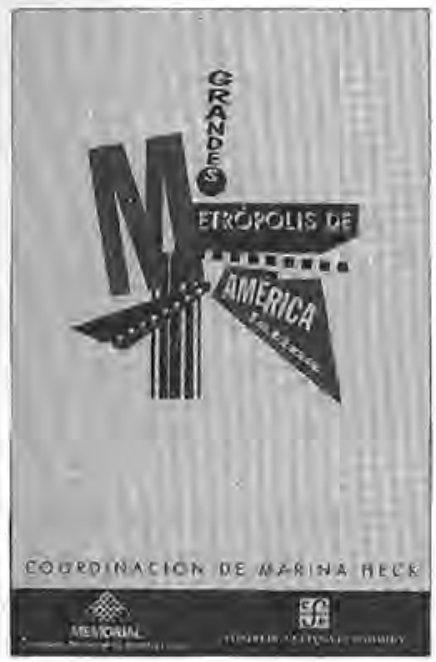

\section{GRANDES METRÓPOLIS DE AMÉRICA LATINA}

de Marina Heck (Coord.)

São Paulo: Fundação Memorial da América Latina, Fondo de Cultura Económica, 1993, 320 p.

por José Roberto Felicíssimo, Sociólogo, Doutor em Ciências Sociais, Professor Assistente-Mestre da FEA-PUC/SP, Consultor.

sta publicação anuncia boas novas ao cavaleiro andante recém-chegado e ao que, há mais tempo, está abrindo o caminho ao caminhar, nas sendas e paragens do território urbano, instalado e expandido pelo domínio ibérico. Reúne as contribuiçōes dos autores convidados ao Encontro - promovido pela Fundação Memorial - que debateu assuntos pertinentes às grandes metrópoles da América Latina: as desigualdades, a prestação de serviços através de intermediários, a modernização e a conseqüente deterioraçấo dos índices de qualidade de vida. Marina Heck, na Introdução, esclarece que "nāo quisemos mostrar exclusivamente o discurso técnico do planejador. Nem ao menos tivemos a intenção de delinear metas para o futuro". No evento produziu-se extenso diagnóstico, com as distintas percepçōes dos autores sobre os vários loci metropolitanos selecionados; contudo, sem a pretensāo de solucionar os problemas identificados e, sim, apresentar um balanço das idéias, tendências e vivências das cidades latinoamericanas.

A diversidade, no caso, não significa dispersão, ou desorientação do guia, nesta caminhada por nossas metrópoles. Pelo contrário, o leitor é conduzido por caminhos e trilhas construídos, historicamente, no embate (e nos muitos combates) de antagonismos manifestos nas relações entre os agentes sociais que buscam seu espaço vital nos limites urbanos da regiăo. Com oportunidade, vários autores mapeiam uma das veias abertas na América Latina: se, por um lado, o discurso do planejador se apóia, fundamentalmente, na questão da implementação de normas através da racionalidade, por outro, a reflexão sobre a cidade esconde um aspecto residual e informal que é percebido como seu lado marginal, sujo ou ilegal. Esse paradoxo, entre a cidade formal e a cidade ilegal, é mencionado por Jorge Hardoy, retomado por Raquel Rolnik - como a cidade legal e a cidade real e reforçado por Heck, para quem a cidade tem duas caras: uma, visivel, legivel e, portanto, capaz de submeter-se a normas; e, outra, invisível, escondida, "ilegal", contudo mais volumosa que a primeira e onde a desordem e a irracionalidade dificultam, quase impedindo, a disciplina e a aplicação de normas cartesianas. Essa realidade pode ser encontrada nos interstícios ilegais da cidade, na periferia, nas favelas, como também nos conventillos e nas ruas. Uma realidade que, a seu ver, coabita incoerentemente com o progresso e com a modernidade, ao mesmo tempo em que é, no fundo, sua própria conseqüência. $\mathrm{E}$, isso, configura o aspecto específico da cultura urbana da América Latina, impregnada pelo modo de vida da periferia.

Está posto, então, em debate - para os autores e aos leitores - o paradoxo universal do planejamento: de um lado, o urbanista bem-intencionado que apresenta soluçöes objetivas e viáveis para permitir a sobrevivência do sistema; e, por outro, a não objetividade, o conhecimento da cidade através de seus símbolos e mitos e das práticas cotidianas de seus usuários, a assimilação de sua magia horizontal, profundamente marcada pela memória, através da qual podemos chegar à essência da questão urbana.

Os dezenove estudos reunidos nesta obra estão distribuídos por três recortes temáticos: Metrópole - mito e memória; Planejamento e gestăo urbana: do passado para o futuro; e Estruturação da metró- 